\title{
Review \\ A Survey of GIS and IoT Integration: Applications and Architecture
}

\author{
Jalal Safari Bazargani ${ }^{1,+}+\mathbb{D}$, Abolghasem Sadeghi-Niaraki ${ }^{1,2,+} \mathbb{D}$ and Soo-Mi Choi ${ }^{2, *}$ \\ 1 Geoinformation Technology Center of Excellence, Faculty of Geodesy \& Geomatics Engineering, \\ K.N. Toosi University of Technology, Tehran 19697, Iran; j.safari24@gmail.com (J.S.B.); \\ a.sadeghi.ni@gmail.com (A.S.-N.) \\ 2 Department of Computer Science and Engineering, Convergence Engineering for Intelligent Drone, \\ Sejong University, Seoul 143747, Korea \\ * Correspondence: smchoi@sejong.ac.kr \\ + These authors contributed equally to this work.
}

Citation: Safari Bazargani, J.;

Sadeghi-Niaraki, A.; Choi, S.-M. A Survey of GIS and IoT Integration: Applications and Architecture. Appl. Sci. 2021, 11, 10365. https:// doi.org/10.3390/app112110365

Academic Editor: Gianni Pantaleo

Received: 17 October 2021

Accepted: 29 October 2021

Published: 4 November 2021

Publisher's Note: MDPI stays neutral with regard to jurisdictional claims in published maps and institutional affiliations.

Copyright: () 2021 by the authors. Licensee MDPI, Basel, Switzerland. This article is an open access article distributed under the terms and conditions of the Creative Commons Attribution (CC BY) license (https:// creativecommons.org/licenses/by/ $4.0 /)$.

\begin{abstract}
IoT, as an emerging technology along with GIS, can result in advanced and user-friendly features in Smart Cities. In order to investigate the capabilities offered by these technologies, this paper provides an overview of GIS and IoT integration focusing on applications and architecture. Specifically, this paper starts with investigating the role of GIS and IoT separately and jointly in different domains. Then, a review of GIS and IoT integration studies is provided to examine how GIS could be used in IoT architecture. The results showed that the capabilities of GIS in dealing with geospatial data and attributes along with offering visualization and analyzing tools make it possible to develop an integrated system benefiting from real-time data collection and real-time monitoring provided by IoT. The presented details would assist researchers in future studies on utilizing GIS and IoT at the same time.
\end{abstract}

Keywords: internet of things; IoT architecture; geospatial information system; visualization

\section{Introduction \\ 1.1. Internet of Things}

Internet-of-Things (IoT) [1-3] concentrates on enabling communication between Things. It is a broadband network that uses standard communication protocols [4] The term "Things" refers to computing devices, objects, etc. which are connected through the Internet, therefore, they have a unique Internet Protocol (IP) address [5,6]. IoT can provide a network, over which data is transferred, and Things in this network would play a role of consumers or providers. Each sensor produces data and passes it to consumers to make them aware of the current state. By 2025, it is predicted that the number of IoT devices will be well over 21 billion devices [7]. Therefore, the impact of IoT in everyday life will be inevitable. As an example, with the development of digital technologies, the presence of IoT in smart city aspects including smart building, smart healthcare, smart education is explicit $[8,9]$. The unquestionable impact of IoT can be observed from viewpoint of both private and business users [10]. Smart homes, assisted robots, etc. are some examples which a private user will experience. On the other hand, automation in manufacturing can be a use case for a business user.

\subsection{GIS}

Geospatial Information System (GIS) [11-14] is a powerful set of tools that deal with capturing geospatial data, managing that data in a database, analyzing and pattern recognition, and finally visualizing information. Reference [15] highlights the intelligence version of geospatial topics in the near future which can be a testimony to the great potentialities of GIS. As the main characterization of GIS, it is capable of describing each 
entity by spatial data through its location and shape. GIS functionalities cover a wide range of applications $[16,17]$. To be more specific, this framework is helpful in dealing with the users' queries which can be divided into three types of naming: Factual, Graphical, and Spatial [11]. The four capabilities of GIS are mentioned at the beginning of Section 1.2. (Capturing, Managing, Analyzing, Visualizing) are involved in the process of answering users' queries. That is to say after the data is captured, according to the type of users' queries, GIS can perform some analysis in order to provide appropriate outputs. Presenting the storage capacities of all reservoirs located in parcels of a city, visualizing the distribution of shopping malls at the city center, locating parcels within $2 \mathrm{~km}$ of a power plant are respectively some examples of Factual, Graphical, and Spatial queries.

\subsection{Motivation}

As it is discussed, the emergence of IoT into real life is getting noticeable $[4,7,9,18]$. Although the rapid growth of technologies will result in addressing a wide variety of problems, it will cause challenges, too. Hence, an integrated version of IoT with other technologies not only would be a great step toward facing those challenges but also can solve the problems more optimally. GIS, with the vast number of functionalities, could be a part of those mentioned integrated versions [19]. Since geography can be considered as an indispensable part of many applications, many studies have been done to research a new layer of IoT [20] and that is the involvement of GIS into it [21]. In addition to playing the role in a new layer of IoT, each node in IoT needs a unique IP which means a unique geographical location. Therefore, the existence of GIS in IoT-based systems is unquestionable. With the capability of dealing with spatial and attribute data, GIS could also be easily scaled up for different applications and locations. Besides, traditional GIS and pure GIS systems suffer from a low level of coordination and automation due to the constrained computing resources and inability to accommodate marginalized groups [22,23]. Therefore, the involvement of IoT in GIS systems can lead to an optimal system that no longer is error-prone, time-consuming as much as before [24]. In conclusion, GIS and IoT can be beneficial to both current IoT or GIS-based systems, and integration of these two technologies is a win-win situation. For the current state of this research field, few papers were found investigating the integration of IoT and GIS in terms of application and architecture at the same time [25]; furthermore, they had focused on specific areas and not explored the whole integration in different kinds of application. The lack of enough review studies for this kind of integration would be another testimony to the significance of this study.

In this paper, GIS and IoT integration studies are reviewed. The purpose is to examine the different combinations of these technologies and see how GIS has been taken into account. The study is based on a two-step approach. In the first step, use cases of IoT and GIS combination are categorized into seven groups and in each category, a summary of related literature is provided. As one of the novelties of this paper, the capabilities and challenges of the systems using only one of these technologies are discussed and at the end, papers benefiting from the integrated versions of IoT and GIS are investigated to see the enhancement compared to the previous systems. Then, as the second novelty of this study, GIS and IoT architectures are defined and studies utilizing GIS in their proposed IoT-based system are summarized to analyze the role of GIS.

The goals that this study aims to satisfy are:

(i) What are the capabilities offered by systems benefiting from just IoT or GIS in each application category?

(ii) What are the capabilities offered by using IoT and GIS simultaneously?

(iii) How GIS can be employed in IoT architecture?

The rest of the paper is structured as follows. The methodology of the study is discussed in Section 2. GIS and IoT integrated use case studies are discussed in Section 3. In Section 4, in addition to introducing IoT and GIS architectures, the architectures of integrated IoT and GIS systems are discussed. The discussion of analyzing studies is addressed in Section 5. Section 6 concludes with a summary and directions for future research. 


\section{Materials and Methods}

At first, several review papers discussing IoT and GIS were examined to obtain some keywords for further steps. Then, with the help of Google Scholar and Scopus, expected articles were exported. In the screening stage, the title and abstract of each paper were read to include or exclude the paper. Finally, considering the possibility of retrieving the full text of articles, appropriate papers were selected for full-text examination. Through this step, data such as application domain, architecture, the role of GIS, targeted challenges, and limitation of papers were extracted, and providing such data was considered as the inclusion criteria for papers. The results of classifying and analyzing the extracted data are discussed in the following section.

\section{GIS and IoT Integration Use Cases}

Nowadays, GIS and IoT-based systems are not only at developers' center of attention but also at officials' and organizations [26-29]. With the wide range of applications provided by these integrated systems $[19,25]$, they are being used in many aspects including urban and rural developments.

Various related literature studied on the application of integrated GIS and IoT systems is discussed in this section. In addition, these studies were categorized into seven groups indicated in Figure 1.

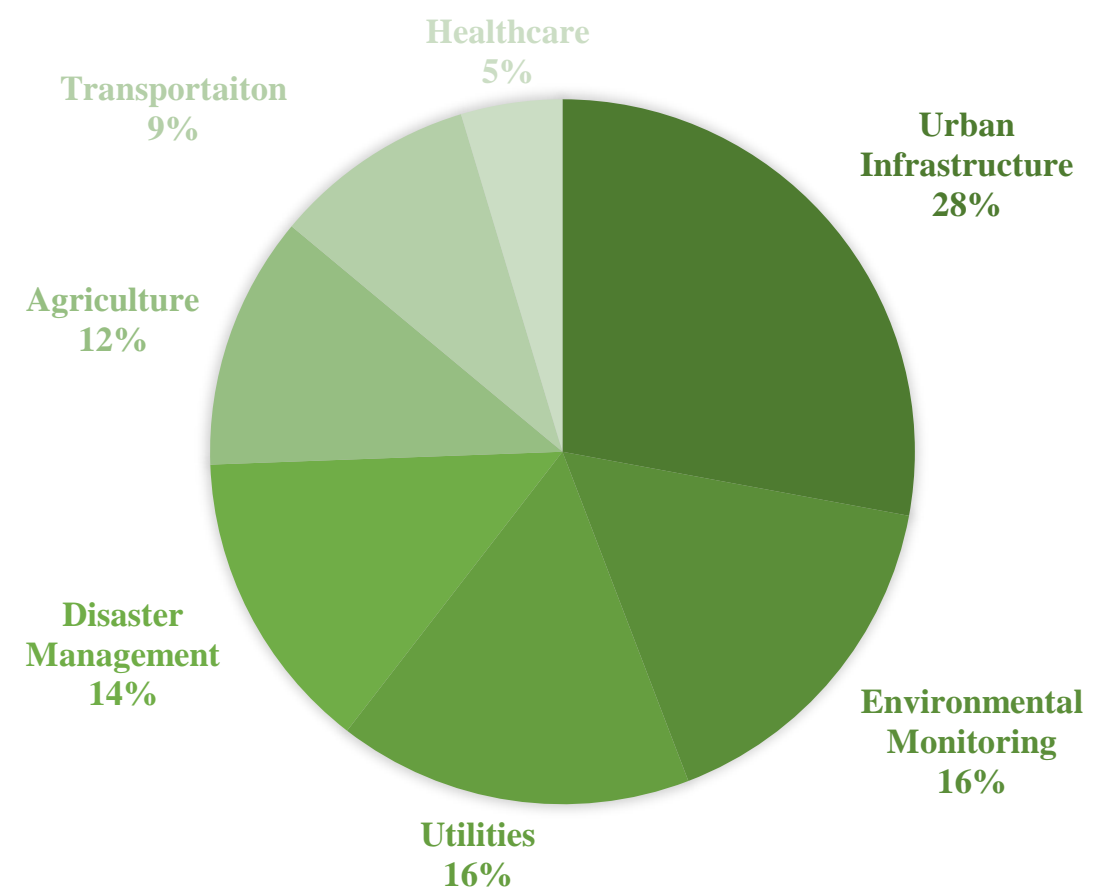

Figure 1. Industry share of GIS and IoT integrated applications.

As it is shown in Figure 1, Urban Infrastructure mostly including smart city-related studies has been the most frequent domain of applications $[8,26,29,30]$. Environmental Monitoring and Utilities shared the same frequency of $16 \%[28,31,32]$. On the other hand, less attention was paid to the Healthcare industry in GIS and IoT integrated point of views [33]. These industry shares can be compared with the estimated market share of IoT applications by 2025 [1] in which Healthcare is projected to have the most economic influence. Therefore, it would be a great opportunity to focus on the Healthcare industry to use the great functionality of GIS simultaneously with IoT.

Some of the studies in each category are discussed in the following sub-sections. 


\subsection{Urban Infrastructure}

Growth estimations of city populations from 3.6 to 6.3 billion by 2050 [34] can be a testimony to a great tendency toward urbanization $[35,36]$. As expected, modern societies are seeking indices and solutions to evaluate urban smartness $[37,38]$ and to enhance citizens' life quality $[35,39,40]$. The endeavor to improve life quality encompasses all aspects of a city such as healthcare [41], transportation [42,43]. IoT is considered as a catalyst in the process of transformation of cities into smart ones [44]. Reference [45] highlights the revolutionary solutions of IoT for infrastructure needs such as Industry 4.0, power and water grids, and smart cities. According to Reference [46], three main areas must be taken into consideration to be improved in order to develop IoT technologies in an efficient way. Those three main areas are sensor-oriented technologies, network services, and energy-related technologies.

Utilizing GIS holds some benefits in the phases of developing a new infrastructure namely planning, designing, construction, and operation $[19,47,48]$. The capability of handling both spatial and non-spatial data makes GIS a great tool for performing efficient management. In addition, marking the ability to provide digital representations of the Earth's surface, Reference [49] suggests developing digital urban infrastructure. With the great functionalities provided by IoT and GIS mentioned above, the integration of these two technologies would result in more effective systems. Reference [44] investigates other technologies like GIS to be integrated with IoT to be used in different aspects of urban infrastructure.

\subsection{Transportation}

Transportation plays a critical role in enabling communication between people. It also provides other types of exchange such as trading and facilitates the movement of people and goods [50]. This category covers a wide range of applications including smart parking [42], public transportation [51], intelligent transportation systems [52]. With the rise in the number of vehicles, modern societies are paying more attention to transportation management $[43,53,54]$ which faces the challenges of efficiency, safety, and sustainability [50]. The optimal managing of traffic not only reduces traffic congestion on peak hours but also can be beneficial for other services such as emergency ones. Therefore, some studies $[55,56]$ are performed to enhance the quality of current related services. Transportation pertains inherently to location, flows, and interactions which GIS is good at dealing with them. The combination of GIS and Transportation called GIS-T [50,57] holds some benefits in facing the problems like transportation planning [58,59], design [60], maintenance [61], and decision-making [62,63]. In Reference [57], GIS-T is discussed in three stages namely the map view, the navigational view, and the behavioral view. The map view stage relates to inventory and description of transportation systems. The second stage, the navigational view, focuses on connectivity and planarity in addition to storing time-dependent attributes. Finally, dealing with transportation-related events as dynamic ones are proposed in the behavioral stage. In order to tackle the future challenges of transportation systems, the combination of WebGIS/cloud computing/big data is suggested in [50]. In addition, IoT by providing affordable sensors together with the proliferation of internet infrastructure can be helpful in GIS-T. Reference [64] proposes an IoT-based ITS constructed by three components namely the sensor system, monitoring system, and the display system. Reference [65] proposes a technique by correlating Global Positioning System (GPS) data and local GIS information to face the challenges of latency and limitations of bandwidth when transmitting the location of vehicles in Intelligent Transportation Systems. As GIS and IoT integration examples, in [66], using GIS, Radio-Frequency Identification (RFID), and cloud computing technologies, a parking navigation system is presented which facilitates finding parking lots for users near their destinations. After processing the gathered data which is converted into GIS-supported formats, users can be informed through their smart mobile devices whether there is an empty parking lot at the parking and if so, the system will display GIS images of empty parking lots and the navigation to them. An emergency management system is proposed in [67] in order to manage public road transport networks that use 
IoT as a means of observing traffics and road infrastructures. In this research, GIS is also exploited to enhance situational awareness and perform some emergency operations.

\subsection{Disaster Management}

The tendency of cities toward modernization especially those exploiting technologies results in a more crowded environment [68]. Urbanization leads to structures built on most of the empty lots which result in low-efficiency rescue plans [69]. Therefore, broadly speaking, disaster management can be considered as one of the main concerns of all societies. Generally, disaster management can be considered into three phases, namely; Preparedness, Response, and Recovery [70]. A beginning phase called mitigation is also mentioned in [71] for disaster management phases.

With the development of technologies, new strategies could be proposed to improve disaster management. Reference [71] explores the application of IoT and other technologies naming RFID, GPS, GIS, and Wireless Sensor Network (WSN) in disaster management approaches. In this research, studies are analyzed according to the technologies and tools they utilized and their studies supporting phase in disaster management.

According to Reference [71], RFID, a valuable technology, has been used in disaster management studies the most. In addition, GIS, being used nearly by $60 \%$, can be considered almost as an inextricable part of disaster management where Reference [72] suggests exploiting GIS due to the advantages over conventional maps. It is also worth mentioning that the capability of GIS as a simulating tool is highlighted in [71] by analyzing studies utilizing GIS and WSN to predict flood damage [73,74].

Many studies have been done on different phases of disaster managing [70,75-77]. An early warning system which can be considered as a Preparedness phase is proposed by [78] to inform about the snowmelt flood. A section related to IoT, called Management Tools, is constructed in this study which includes an information mining sub-section dealing with spatial and sensor data mining. In turn, GIS functionalities are used to perform spatial analysis of those gathered data.

Particularly for phase Response, using GIS and IoT a system is proposed in [79] to improve evacuation efficiency through analyzing the impact of smoke on evacuation. In this study, in order to collect high-resolution information in real-time and analyze the performance, IoT is exploited. The functions in GIS are used to process the parameter information of the environment and guide people to exits whenever a fire occurs. Another response system is presented in [80] so as to face volcanic disasters. In this study, a damage prediction model based on spatial information is used to enhance the effectiveness of the system. They use GIS as a tool to display the simulation and related tables and charts. Reference [81] exploits IoT, GIS, and GPS respectively as collection, mapping, and location finding tools to study forest fire monitoring systems to enhance the accuracy and rapidness of locating the position of fire. Another fire-related study is performed in [69] which is the presentation of a fire rescue emergency plan by integrating technologies like IoT, GIS, Virtual reality, and indoor positioning. The combination of GIS and VR is used to provide an interface with ease-of-use capability and training courses for fire forces. A weather disasters monitoring system is accomplished in [82] for alerting about severe weather changes. Using ArcGIS tools, a model is provided to observe emergency scenarios according to the data collected by weather sensors. In the proposed system, by allocating a server for GIS, it is responsible for displaying the weather parameters data and visualizing vulnerable regions on a map.

According to what was discussed, there is a need to investigate the integration of GIS and IoT in studying disaster management phases particularly the Recovery phase.

\subsection{Environmental Monitoring}

The noticeable rate of increase in the urban population has caused many problems in urban areas [83]. In recent years many organizations established environmental quality management systems [84] that cover a wide range of issues including how to face natural 
disasters or how to decrease the pollution of air $[85,86]$. IoT can be beneficial in implementing environmental managing systems such as real-time monitoring by means of storing the data, transmission, and processing remotely. Reference [87] presents a system that monitors water quality by measuring five parameters like the turbidity and temperature of the water using IoT. The monitoring system proposed in this study diminished the time and costs in assessing water quality in reservoirs. In addition to IoT, GIS can play a significant role in monitoring systems as well [88-90]. As mentioned in [89] the ability of GIS to handle geometric, thematic, and temporal geospatial data makes it suitable for environmental data management. Therefore, the integration of GIS and IoT studies would provide more advantages at the same time in environmental monitoring systems. For example, an environmental quality management information system is designed by [32] exploiting GIS, GPS, IoT, and RFID. The proposed system benefit from the spatial data analysis capability of GIS which results in enhanced decision support for environmental quality management. Reference [31] studied the functionalities of environmental protection systems benefiting from GIS and IoT by proposing an intelligent system. Their main goal relates to the enhancement of management and decision-making level.

The prominent purpose of these studies can be considered as to provide a better future and healthy living for all people. An air quality monitoring system is proposed by [91] to observe the air quality through a web server using IoT gas sensors to collect information about toxic and harmful gases. GIS is also beneficial in their study and that is the capability to display the areas with air pollution information. Using GIS, Remote Sensing (RS), and IoT a water quality monitoring system is presented in [92]. They concluded that the use of GIS and RS can facilitate processes such as data collection and monitoring, site selection for a source of water, and quick identification of a site that is in need of attention.

\subsection{Agriculture}

Broadly speaking, agriculture can be considered as an inherently geospatial practice [93] which not surprisingly can be pertained to GIS subjects. According to Reference [93], GIS and spatial decision support hold some benefits in agriculture such as Enhancing the efficiency of food production systems [94-96], Managing pests and diseases [97-100], Minimizing soil erosion [101-103], Preserving biodiversity [104,105], and simulating the effects of climate change [94,106]. As mentioned in [107], due to a rise in migration to urban areas, agriculture is facing some difficulties. They propose smart agriculture techniques based on IoT which exploit WSN for measuring soil properties and environmental factors continuously. They control the data, gathered by various sensors planted in the farm, through remote devices or internet services. The role of sensors in agricultural applications is so essential so that in Papers $[108,109]$, besides using humidity and temperature sensors, an image sensing node is also exploited to monitor the changes in crop fields by taking images. Combining GIS with other technologies such as IoT would be a great step toward improving current systems in the mentioned aspects in agriculture since utilizing just mere geospatial data and analysis will no longer perform well in some agricultural issues [110]. Using GIS, IoT, and socket programming, a Detection and Warning System of Rice Disease is proposed in [111] in which statistics such as air humidity, illumination, water temperature, etc. are gathered and finally the polluted regions are displayed on the map as warning massages which help the farmers with preventing the spread of a rice disease. A Precision Agriculture Management System (PAMS) is proposed by [27] based on IoT and WebGIS. WebGIS is used as a tool for providing basic spatial information, positioning, and a mobile calculation platform for the system. Monitoring farmlands remotely in real-time can be accessed using the functions provided by WebGIS to collect, process, and display the appropriate data. In their study, collecting agricultural production data is performed using IoT sensors. As the integration of GIS and IoT will result in an improvement in the production and economical section of agriculture, [112] presents a DC-driven tool which is a power switch to optimally control the appliances used in agriculture. To maximize production and gain more profit of land, GIS is used to obtain the localized satellite data and combine it with on-site IoT sensors. 


\subsection{Utilities}

The application of smart utilities has gotten more attention in modern cities [113,114]. Smart utilities cover a wide range of applications such as Waste, Water, Lighting, and Logistic Management [25,115]. There is a tendency toward developing an intelligent utility system aiming at the delivery of city utilities to be efficient, reliable [113]. The integration of technologies such as IoT and GIS lead to making faster decisions in managing and controlling utility systems $[115,116]$.

For Waste Management, GIS plays a significant role mostly in optimizing the municipal waste collection system [117,118], vehicle routing, and scheduling the systems [119-121]. GIS helps decision-makers in analyzing and simulating different spatial scenarios by providing an advanced modeling framework [117,122]. The proliferation of sensors and the capabilities of IoT in real-time managing and monitoring holds some benefit in the waste collection too [123]. Reference [124] proposes a dynamic routing algorithm by using the cost efficiency potential of IoT. Reference [123] marks that the traditional waste collection systems were treated in a static manner by classical tools and approaches. They propose a query-based dynamic scheduling model to deal with the challenges caused by data streams. As an example of GIS and IoT integration, Reference [125] introduces a waste bin monitoring system in which RFID and GIS are used respectively to collect data and as a visually monitoring platform. Reference [126] proposes a GIS-IoT-based garbage collector monitoring system to gather statistical data about the containers in different parts of the city.

For Lighting, two problems are faced by most researchers. First, lighting data does not satisfy the proper spatial resolution. Besides, collecting data by measurement campaigns is costly $[127,128]$. A networked lighting system would be advantageous in local optimizations of illumination due to the presence of sensors [129]. Integrating such systems with IoT will result in remote management [128]. In addition, smart lighting is introduced as one of the most relevant uses of IoT in smart cities by The IoT European Research Cluster (IERC) [18]. The research performed by [127] indicates a need for a more effective lighting infrastructure in urban areas not only to bring luminance but also to provide safety for citizens. Therefore, they proposed a local illuminance GIS mapping. GIS is used to store automatically the ID of the sensors, light measurement data, the timestamp of the measurement, and the GPS position. Besides a tool for storing data, GIS is responsible for processing and displaying the information through the map of the quality of streetlights which can also be interpreted by quantitative indexes which area suffers from a low-security level. Therefore, GIS as a mapping tool and IoT by the cost-efficiency potential can be beneficial in lighting issues of cities. Traditional lighting systems suffer from a lack of efficiency in monitoring and are costly in energy and price too [130]. In this research, a monitoring and control scheme by exploiting GIS and ZigBee is proposed to analyze the real-time operating parameters of lighting equipment in order to come up with a strategy to control the system. The use of GIS as a visualization tool, and the use of IoT as an energy-saving implementation were noticeable in their study.

For Water Management, digital maps and special tools in GIS can enhance the efficiency of sewerage networks [131]. ArcCatalog and ArcGIS can be used as network design and analysis tools [132]. The network, designed in ArcCatalog, holds benefits in designing and implementing sewerage systems [133,134], analyzing and monitoring such systems $[135,136]$, and simulating like that of urban sewerage flow volume $[137,138]$. Reference [139] marks the significant role of monitoring and controlling systems in water supply and sewerage facilities. With the development of sensing in IoT, they emphasize the use of this technology to operate and maintain water supply and sewerage systems. As an example of GIS and IoT integration, Reference [140] examined the concentration and influence of toxic gases in the urban underground sewage pipe network by the data gathered by IoT. GIS is used as a tool for pipeline 3D visualization, real-time display of accident disposal, material distribution, and path visualization. 


\subsection{Healthcare}

Health care refers to a system that involves the maintenance and enhancement of medical services. Therefore, a global struggle is happening to improve the quality of healthcare services [141-143]. Reference [144] highlights that GIS, taken together with non-spatial factors, is being used increasingly in healthcare. Discussing the role of GIS in healthcare, the examples of the use of GIS include those concerned with improving the quality of care [145], analyzing the spatial distribution of diseases [146-148], planning and assessing location-based services [149,150], enhancing the accessibility of services [151,152]. Section 1 of Reference [150] investigates the role of GIS in disease mapping and spatial analysis. They describe the basic elements of geographical analysis, cartographic operations relevant to public health, disease mapping from a statistical standpoint, and clustering methods. In addition, in Section 3, GIS applications in healthcare planning and policy are discussed. For the role of IoT, in Reference [153] two applications of IoT in medical systems namely Clinical Care and Remote Real-time Electrocardiogram (ECG) Monitoring are introduced. For example, in Clinical Care applications, Masimo Radical-7 can be used to monitor the physiological statuses of patients remotely and report it to a clinical staff [154]. IoT and healthcare studies also point out the implementation aspect. Reference [155] describes the implementation of an IoT-based In-hospital healthcare system using ZigBee mesh protocol to monitor the physiological parameters of patients. Reference [156] investigates technological solutions in order to facilitate clinical knowledge transfer and gathering using IoT. Sensors and actuators provided by IoT can be beneficial in evaluating the performance of medical equipment [157]. The condition of patients can also be monitored by tracking their medicine consumption through embedded sensors [154]. As discussed above, healthcare studies vary in topics and target area and the integration of IoT and GIS would provide valuable features. Reference [158] proposed a ubiquitous health system as remote monitoring of the patient system. Using smart-watches data like a heartbeat is measured and is analyzed by GIS according to the position of the patient. Finally, the information is sent to the patient-doctor via smartphones. As another scenario, a risk management system based on IoT, BIM, and GIS is proposed by [33] to monitor real-time risk factors and provide more effective responses. The processing layer of their system hosts GIS which provides the information related to hospitals located near the area they are monitoring with a set of computing and simulation tools.

\section{Integrated IoT and GIS Architectures}

In the previous section, the roles of GIS and IoT are discussed in different domains. In addition, the advantages of the integration of these two technologies are also mentioned. To investigate how GIS can be used in IoT-based systems in terms of architecture, first of all, IoT architecture and GIS components are defined. Then, studies utilizing GIS in IoT systems are analyzed in order to specify that in which layer GIS can be involved.

\subsection{IoT Architecture and IoT Elements}

Internet of Things has tremendously evolved in the last years and different architectures have been proposed by researchers $[1,159,160]$. There is a three-layer architecture developed in the early stages of these studies $[1,161,162]$ which consists of the Perception layer, Network layer, and Application layer. A five-layer architecture is also used by [163-165]. Perception, Transport, Processing, Application, and Business layers are proposed in this type of architecture. This study considers a five-layer architecture for IoT which is shown in Figure 2. 


\section{Business layer}

\section{Application layer}

\section{Processing layer}

\section{Transport layer}

\section{Perception layer}

Figure 2. The architecture of IoT.

The Perception layer consists of sensors for sensing and gathering information about the environment [159]. Depending on the purpose of the system, the type of sensors including RFID, IR sensors, or other network sensors and their collected data may differ. Providing identification and information storage like RFID tags, information collection like sensor networks, and information processing like embedded edge processors is the aim of using these hardware elements [165]. The collected data is passed to the Transport layer also known as the Network layer. This layer acts as the human nerves [166] and is responsible for connecting to the processing system to transmit the information gathered from sensor devices. A wide range of communication networks like wired or wireless ones, the Internet, etc. can be brought into the perception layer. 3G/4G, ZigBee, Wi-Fi, Bluetooth are some of the communication mediums used in this layer. According to the similarity of the Network layer to human nerves, the Processing layer can act as a brain [166]. This Layer is designed to store, analyze, and process the information received from the Perception layer through the Network layer. Direct access to a database to store the information is provided using technologies like cloud and fog computing. The application layer plays the role of an interface between the system and the user. Due to the processed data and the goal of the designed system, this layer is responsible for delivering the appropriate application to the user [165]. The application covers a wide range of cases. The Business layer is responsible for managing the whole IoT system activities by generating different business models [1] and is out of the scope of this study.

According to Reference [1], the elements of IoT are Identification, Sensing, Communication, Computing, Services, and Semantics. The first element deals with identifying objects uniquely to satisfy their demands. Sensing is responsible for collecting data using various sensors and transferring it to a database often in the cloud. The third element, Communication, consists of technologies that are capable of providing a heterogeneous connection between objects. Computing, comprising of devices and software, processes the gathered data. Services and Semantics deal with acquiring suitable knowledge to present appropriate services. 


\subsection{GIS Components and Elements}

The integration of data, software, hardware, methods, and human-shown in Figure 3-can lead to a GI System $[17,167,168]$. In addition to being a source of valuable geospatial data, GIS can provide data storage and data management facilities [168]. Therefore, data can be considered as the most prominent component of a working GIS because of providing. Any kind of data is acceptable in GIS as long as geospatial data is involved in it. Software is a set of tools provided to store, analyze, and display data. A graphical user interface, a database management system, a set of tools like Toolbox in ArcMap are some key software components. Hardware refers to the device on which GIS can be used. Nowadays, different sets of devices with different configurations or topology in a network can play the role of hardware in GIS. Considering the need of the employer, and the existing facilities, the optimum method to design a GIS according to the employer's expectation is needed. The last component of a working GIS which is human can be categorized into two groups. The ones who are responsible for the design and maintenance of a GIS can be called technicians.

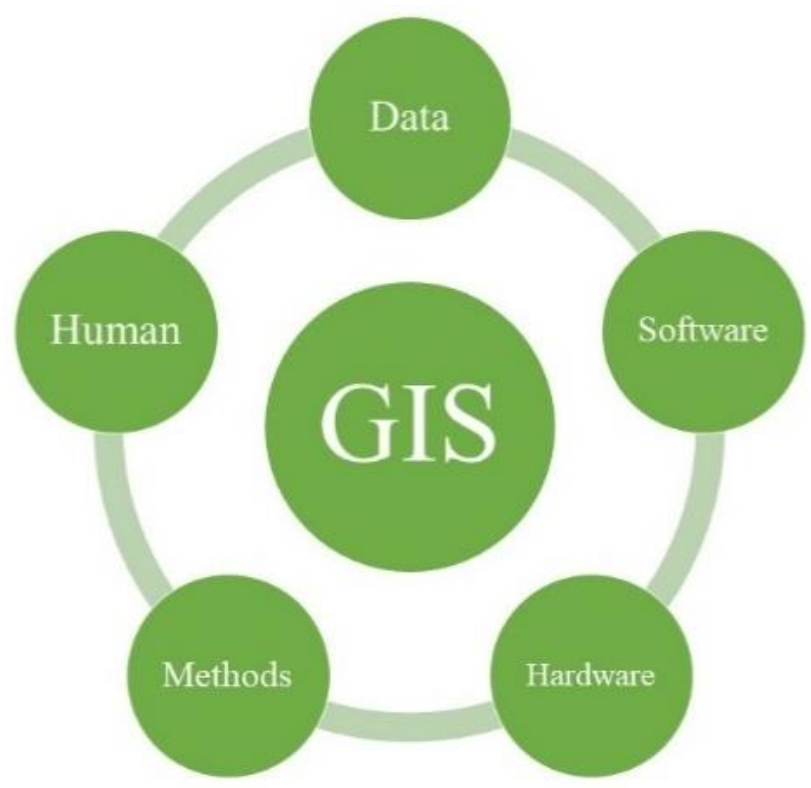

Figure 3. GIS Components.

The elements of GIS, namely data acquisition, data management, data query, vector data analysis, raster data analysis, and data display are discussed in [168]. These elements may not be sequential as though it is in IoT.

\subsection{GIS and IoT Integration Architecture}

The use of GIS in IoT systems can result in more dimensions and possibilities to IoT-related applications [25] since GIS is capable of dealing with spatial and attributive data gathered by sensors. After discussing what the components of GIS and architectures of IoT are, the integration of these two technologies can be studied through investigating how GIS can be used in IoT architectures. The articles reviewed in this section are shown in Table 1.

As illustrated in Table 1, GIS has found its way into IoT systems in the third and fourth layers of IoT architectures. The most noticeable presence of GIS-the column labeled Other-is its functionality of providing analysis techniques and tools in the processing layer. In the following sub-sections, more discussion of this categorization is provided. 
Table 1. A summary of GIS involvement in IoT architecture in each article.

\begin{tabular}{|c|c|c|c|c|c|}
\hline \multirow[b]{2}{*}{ Article } & \multicolumn{3}{|c|}{ Processing Layer } & \multicolumn{2}{|c|}{ Application Layer } \\
\hline & Data-Related & Visualization & Analysis & Mobile GIS & Web GIS \\
\hline [26] & & $\sqrt{ }$ & $\sqrt{ }$ & & \\
\hline [27] & $\sqrt{ }$ & & $\sqrt{ }$ & $\sqrt{ }$ & \\
\hline [28] & & & $\sqrt{ }$ & & \\
\hline [29] & $\sqrt{ }$ & & $\sqrt{ }$ & & $\sqrt{ }$ \\
\hline [25] & & $\sqrt{ }$ & $\sqrt{ }$ & & \\
\hline [30] & $\sqrt{ }$ & & & & \\
\hline [31] & & & $\sqrt{ }$ & $\sqrt{ }$ & \\
\hline [33] & $\sqrt{ }$ & & $\sqrt{ }$ & & \\
\hline [65] & $\sqrt{ }$ & & & & \\
\hline [78] & & & $\sqrt{ }$ & & \\
\hline [79] & & & $\sqrt{ }$ & & \\
\hline [82] & & & $\sqrt{ }$ & & \\
\hline [92] & & & $\sqrt{ }$ & & \\
\hline [111] & & $\sqrt{ }$ & & & $\sqrt{ }$ \\
\hline [112] & & & $\sqrt{ }$ & & \\
\hline [127] & $\sqrt{ }$ & & $\sqrt{ }$ & & \\
\hline [140] & & $\sqrt{ }$ & $\sqrt{ }$ & & \\
\hline [169] & & & $\sqrt{ }$ & & \\
\hline [170] & $\sqrt{ }$ & $\sqrt{ }$ & $\sqrt{ }$ & $\sqrt{ }$ & \\
\hline [171] & & $\sqrt{ }$ & & & \\
\hline [172] & & & $\sqrt{ }$ & & \\
\hline [173] & & $\sqrt{ }$ & & & $\sqrt{ }$ \\
\hline [174] & & $\sqrt{ }$ & $\sqrt{ }$ & & \\
\hline [175] & $\sqrt{ }$ & & & & \\
\hline [176] & & & $\sqrt{ }$ & & \\
\hline [177] & & $\sqrt{ }$ & $\sqrt{ }$ & & \\
\hline [178] & $\sqrt{ }$ & & & & \\
\hline [179] & & $\sqrt{ }$ & & & \\
\hline
\end{tabular}

\subsubsection{GIS in Processing Layer}

To be more specific, the involvement of GIS in IoT architecture in the processing layer is categorized into three types, namely data-related, visualization, and other GIS functionalities which are mostly analysis tools.

\section{Data-Related}

The engagement of geospatial information in IoT systems can result in an improved IoT application with more dimensions and possibilities [25]. Nowadays, there are so many geodatabases containing a wide range of information gathered for different purposes. The following articles used GIS as a source of information or as a tool for storing data in their designed IoT systems.

In Intelligent Transportation Systems, the location of vehicles is required to be transmitted to the cloud but some limitations like the ones caused by bandwidth are being emerged [65]. They proposed a method of compressing the GPS data before transmitting it 
to the cloud. As mentioned earlier, processes related to cloud computing are performed in the Processing layer. In the proposed algorithm, GIS provides the local information to help the algorithm with finding the correlation of GPS data of vehicles in a much more precise way. This help consists of providing the answer to the queries about the minimum distance between roads and waypoints.

Real-time detection of logistic geographical positions by RFIDs through the Internet of mobile phones in IoT is performed to achieve the aim of positioning in Logistic Geographical Information Detecting Unified Information Systems [178]. In their study, the geographical information database is used to represent the detailed address information by geocoding.

Reference [30] proposed two distributed IoT platforms improve energy management in smart cities. The purpose of DIMMER, their first proposed platform, is to make different devices capable of interoperating to share heterogeneous information about energy distribution systems, buildings, and apartments. In their work, GIS is used along with the Building Information Model (BIM) 3D parametric models and System Information Model (SIM) to find the correlation of energy-related information.

The general framework of the risk management system proposed by [33] discussed in Section 3.7 clearly indicates the presence of GIS in the processing layer.

Reference [170] presents a system based on IoT, web services, and GIS which is used to provide real-time Web Map Service (WMS). The system is capable of representing a web map of real-time outage status. The GIS server used in their study is responsible for providing and storing the required data in their web map and feature services.

Reference [29] collection and geovisualization of big data from multiple sources like IoT devices and satellites are discussed through a City Geospatial Dashboard. GIS provides a road network model in order to represent the hourly link population and flow directions.

As smart cities aspects becoming a great topic for researchers, GIS in [175] is used to provide the data input for the K-means clustering algorithm for optimizing a dynamic traffic network to analyze real-time traffic data.

The studies [27,127], discussed respectively in Sections 3.5 and 3.6, also used GIS as a data source.

Visualization

GIS has the capability of merging all kinds of data which has a spatial component. This leads to enabling the user to create layers of information and visualize them [178].

The study performed by [179] focuses on providing a method to facilitate the GISbased fusion information which resides in building models and the information gathered by sensors. In that paper, GIS is used to represent the information provided by multiple resources such as IoT sensors, building models, and virtual sensors. Therefore, GIS plays the role of an integration platform, as well as a visualization one for the integrated information.

As technology develops, more and more devices are being connected to the Internet and producing a huge amount of data $[180,181]$. The integration of GIS and IoT can result in mapping recourses on digital layers. Several types of visualization of the collected and analyzed data on the map can be performed using GIS including, (i) visualization of moving observation (map service), (ii) visualization of stationary observation (map service), (iii) visualization of discrete observation (map service), and (iv) visualization of observations (feature service) [25].

With the development of urban landscapes, managing different aspects of a smart city has become a challenge [37,38]. Reference [26] studies the use of real-time spatial analytics integrated with Information and Communication Technology (ICT) to face the challenges in smart cities. Nowadays many communities and organizations achieved cost savings and improvements in life quality by using the great functionalities of real-time GIS. Real-time GISs are used as a means of combining sensors from the environment and home to manage communities in an efficient and intelligent way by visual platform [171]. 
Based on IoT, GIS, and spatiotemporal analysis, Reference [140] examines the concentration and influence of toxic gases in the urban underground sewage pipe network of Chongqing City. Pipeline 3d visualization, real-time display of accident disposal, material distribution, and path visualization are some types of visualization provided in their study.

Reference [173] proposes an information management (IM) solution using hybrid storage architecture based on a Virtual Reality version of WebGIS. This IM is used in the data-storage management of Building Information Models (BIM).

A real-time monitoring plan of the pipeline covering gas, heat, and other types of underground pipelines in the campus is proposed by [174]. Besides real-time monitoring, locating the point of failure in the system is achieved through combining the monitoring data with geographic information.

As mentioned in the previous section, GIS in [170] is responsible for displaying a web map of real-time outage status. Besides, GIS helps with displaying the rice disease regions on a map in [111] discussed in Section 3.5.

Analysis (Other Functionalities of GIS)

Geography can be considered an indispensable part of IoT since all physical objects occupy a room in space or time. The same can be true for the produced data by sensors. The location, dimension, and orientation of these objects can lead to many spatial relationships between them [182]. With the great functionalities of GIS, analyzing these relationships can be helpful to address the challenges we are facing in IoT-based systems. These functionalities of GIS are discussed in [183] and are categorized into six different analytical methods of geospatial analysis namely, Geometric Measures, Data Mining, Basic Analytical Operations, Basic Analytical Methods, Network Analysis, Surface Analysis, and Geostatistics.

With the rapid tendency to move to urban areas [35] and an over-utilization of land and sea resources, the quality of water plays a prominent role in people's appropriate areas for living. Using IoT, GIS and remote sensing technology, Reference [92] proposes a water quality monitoring system. GIS is used to divide the Pacific Island Countries into different regions which would be involved in identifying the specific location.

The Studies [78,79] mentioned in Section 3.3 use GIS functionalities to process their information.

\subsubsection{GIS in Application Layer}

GIS can provide its capabilities within the Web and mobile services which can be utilized in the Application layer of IoT architecture. With the development of web technologies, many services are provided for users without many locational restrictions [184]. Nowadays the capabilities of GIS including the visualization of spatial data and its processing tools can be accessible for users through web services [185]. Therefore, many organizations are inclined to use the Web version of GIS to simultaneously benefit from the advantages of Web technology and GIS [186]. In [29,111,173] Web GIS is used to provide the geovisualization of spatial data.

Mobile GIS is another solution to adopt GIS services in mobile devices [187]. This form of the GIS would help users to tackle the problems requiring real-time field mapping and positioning information [188]. Most of the functionalities of GIS discussed earlier could be brought up in Mobile GIS, therefore, users can take advantage of their portable GIS devices. The prominent components of a Mobile GIS are hardware, software, wireless communication, and GPS which also exist in IoT. The studies $[27,31,170]$ use Mobile GIS in their proposed systems.

\section{Discussion}

The functionalities offered by IoT and GIS make it suitable for developing various systems in different domains. In Section 3, the role of GIS, IoT, and the integration of 
these two technologies in different applications are discussed. A summary of the survey is provided in Table 2.

Table 2. A summary of the role of GIS, IoT, and IoT-GIS in different domains.

\begin{tabular}{|c|c|c|c|}
\hline Application & The Role of GIS & The Role of IoT & $\begin{array}{c}\text { Advantages of IoT-GIS } \\
\text { Integration }\end{array}$ \\
\hline Urban Infrastructure & $\begin{array}{l}\text { In phases of Planning, } \\
\text { designing, constructing, } \\
\text { and operating of } \\
\text { development of an } \\
\text { infrastructure }\end{array}$ & $\begin{array}{ll} & \text { Sensing } \\
\text { - } & \text { providing network } \\
\text { - } & \text { services } \\
\text { energy-related } \\
\text { optimization }\end{array}$ & $\begin{array}{l}\text { - A catalyst and } \\
\text { supplement in efficient } \\
\text { managing systems }\end{array}$ \\
\hline Transportation & $\begin{array}{l}\text { - } \quad \text { Planning, design, } \\
\text { maintenance, } \\
\text { and decision-making } \\
\text { Map view, navigational } \\
\text { view, and behavioral view }\end{array}$ & $\begin{array}{ll}-\quad \text { Sensor system } \\
\text { - }\end{array}$ & $\begin{array}{ll}\text { - } & \text { Visualization } \\
\text { - } & \text { Enhancement situational } \\
\text { awareness }\end{array}$ \\
\hline Disaster Management & $\begin{array}{ll}\text { - } & \text { Digital maps } \\
\text { - } & \text { Mapping } \\
\text { - } & \text { Simulation tool }\end{array}$ & $\begin{array}{l}\text { (Real-time) information } \\
\text { Collection }\end{array}$ & $\begin{array}{l}\text { Enhancement of } \\
\text { management system }\end{array}$ \\
\hline $\begin{array}{l}\text { Environmental } \\
\text { Monitoring }\end{array}$ & $\begin{array}{ll}- & \text { Data management } \\
\text { - } & \text { Visualization }\end{array}$ & $\begin{array}{ll}\text { - } & \text { Data collection } \\
& \text { Real-time monitoring }\end{array}$ & $\begin{array}{l}\text { Enhancement of } \\
\text { management and } \\
\text { decision making }\end{array}$ \\
\hline Agriculture & $\begin{array}{ll}- & \text { Minimizing soil erosion } \\
- & \text { Preserving biodiversity } \\
- & \text { Simulating the effects of } \\
& \text { climate change }\end{array}$ & $\begin{array}{l}\text { - } \\
\text { - } \\
\text { factors } \\
\text { Image sensing for } \\
\text { monitoring changes }\end{array}$ & $\begin{array}{l}\text { Improving the defects of } \\
\text { mere geospatial analysis }\end{array}$ \\
\hline Utilities & $\begin{array}{ll}\text { - } & \text { Optimizing municipal } \\
\text { - } & \text { Vystem } \\
& \text { Sehicle routing and } \\
\text { - } & \text { Help decision makers in } \\
& \text { analyzing and simulating } \\
\text { different scenarios } \\
\text { - } & \text { Providing modelling } \\
\text { - } & \text { framework } \\
\text { - } & \text { Dapping } \\
\text { Digital maps }\end{array}$ & $\begin{array}{l}\text { Real-time managing and } \\
\text { monitoring-remote } \\
\text { management } \\
\text { - } \quad \text { Cost efficiency potential }\end{array}$ & $\begin{array}{l}\text { - Faster decision making } \\
\text { in managing and } \\
\text { controlling utility } \\
\text { systems }\end{array}$ \\
\hline Healthcare & $\begin{array}{ll}- & \text { Analyzing spatial } \\
\text { distribution of diseases } \\
\text { - } & \text { Planning location-based } \\
\text { - } & \text { Services } \\
\text { Enhancing accessibility of } \\
\text { - } \quad \text { Carvices }\end{array}$ & 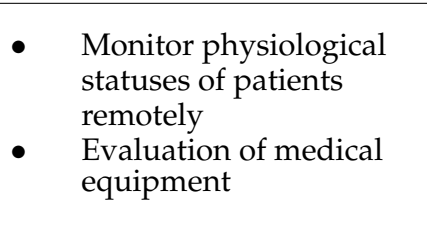 & $\begin{array}{ll}- & \text { Visualization } \\
\text { - } & \text { Enhancement of } \\
\text { monitoring systems }\end{array}$ \\
\hline
\end{tabular}

As discussed in Section 4.3, the most significant presence of GIS in applications mentioned in Table 2 can be categorized into data, visualization, and analyzing tools. The capability of providing types of data, such as digital maps, makes GIS appropriate to be utilized in transportation, disaster management, and healthcare. Routing analysis and decision-making support are the noticeable roles of GIS in Transportation and Utilities. In applications that involve predictions and in which many scenarios could happen, GIS by providing framework models and simulating tools can be useful to analyze possible scenarios. That is the reason, GIS has shown great applications in disaster management, agriculture, and utilities.

The potentialities to collect data by various types of sensors and to monitor the system both in real-time are considered as main IoT advantages. Considering the real-time capabilities along with the functionalities offered by GIS make the idea of integrating these two technologies an efficient one. Monitoring and controlling in real-time will help decisionmakers to take suitable measurements faster. Worth noticing, real-time visualization is an 
essential part of monitoring which can be accessed through the integration of GIS and IoT. Integration of GIS in IoT.

By analyzing Sections 3 and 4.3, the connections between elements of IoT and GIS can be concluded as indicated in Figure 4.

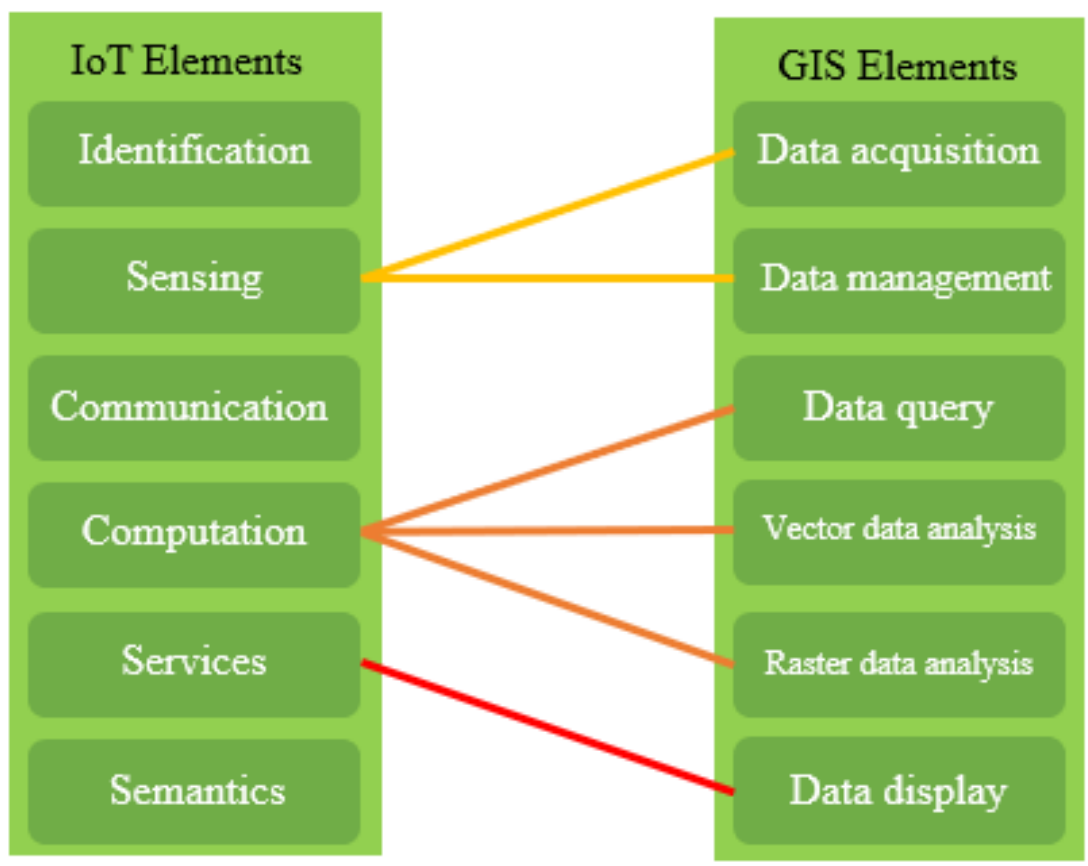

Figure 4. The connection between the elements of IoT and GIS.

As illustrated in Figure 4, sensing in IoT and acquisition and management of data in GIS can be pertained to each other. In other words, the sensing element can provide the data needed in GIS. Computation in IoT, which involves processing the data, can utilize the analysis offered by GIS to deal with geospatial and non-geospatial data. The potentialities of visualization-data display-offered by GIS can be helpful in services. The noticeable point of Figure 4 is that each element of GIS is somehow connected to IoT which indicates the various types of benefiting from GIS in IoT-based systems.

\section{Conclusions}

With the surging trend toward utilizing smart devices and the steep rise in manufacturing these devices, the appearance of a more modern society is unquestionable. IoT is responsible for making communication possible between devices and humans and GIS has the capability to deal with geospatial information. Therefore, the integration of IoT and GIS will lead to smarter and more efficient projects. This paper reviews IoT and GIS-related studies satisfying two goals namely: (1) examining the role of each technology solely and jointly by categorizing the studies into seven application domains, and (2) investigating how GIS is involved in IoT architecture. Considering the three main applications called data-source, visualization, and analysis tools, GIS can play a role in IoT-based systems. Additionally, the real-time data collection and monitoring along with the capability of GIS to deal with geospatial data and attributes makes it a suitable choice for addressing many challenges.

There are four main areas about which future research can study. The first can be thinking of a new target area to be dealt with utilizing IoT and GIS functionalities at the same time in an integrated system. The second area would be to focus on exploiting the whole potentialities provided by IoT and GIS to improve current systems to more efficient and reliable versions. Next, as mentioned at the beginning of Section 1.3, the integration and improvement of technologies and systems might lead to new challenges. Simply put, 
although the integration of IoT and GIS holds many benefits, it is required to study the challenges of these new integrated systems. On a final note, temporal data, representing a state in the time, was not carefully investigated by the authors. Hence, considering this type of data apart from or along with the real-time data in future studies is also suggested.

Author Contributions: Conceptualization, J.S.B. and A.S.-N.; methodology, J.S.B. and A.S.-N.; validation, J.S.B., A.S.-N. and S.-M.C.; formal analysis, J.S.B.; investigation, A.S.-N. and S.-M.C.; writingoriginal draft preparation, J.S.B.; writing - review and editing, A.S.-N. and S.-M.C.; visualization, J.S.B. and A.S.-N.; supervision, A.S.-N. and S.-M.C.; funding acquisition, S.-M.C. All authors have read and agreed to the published version of the manuscript.

Funding: This research was supported by the Ministry of Trade, Industry and Energy (MOTIE) and Korea Institute for Advancement of Technology (KIAT) through the International Cooperative R\&D program (Project No. P0016038) and the Ministry of Science and ICT (MSIT), Korea, under the ITRC support program (IITP-2021-2016-0-00312) supervised by the IITP.

Institutional Review Board Statement: Not applicable.

Informed Consent Statement: Not applicable.

Data Availability Statement: Not applicable.

Conflicts of Interest: The authors declare no conflict of interest.

\section{References}

1. Al-Fuqaha, A.; Guizani, M.; Mohammadi, M.; Aledhari, M.; Ayyash, M. Internet of things: A survey on enabling technologies, protocols, and applications. IEEE Commun. Surv. Tutor. 2015, 17, 2347-2376. [CrossRef]

2. Vermesan, O.; Friess, P.; Guillemin, P.; Gusmeroli, S.; Sundmaeker, H.; Bassi, A.; Jubert, I.S.; Mazura, M.; Harrison, M.; Eisenhauer, M. Internet of things strategic research roadmap. Internet Things Glob. Technol. Soc. Trends 2011, 1, 9-52.

3. Peña-López, I. ITU Internet Report 2005: The Internet of Things; International Telecommunication Union (ITU): Geneva, Switzerland, 2005.

4. Madakam, S.; Lake, V.; Lake, V.; Lake, V. Internet of Things (IoT): A literature review. J. Comput. Commun. 2015, 3, 164. [CrossRef]

5. Al-Ali, A. Role of internet of things in the smart grid technology. J. Comput. Commun. 2015, 3, 229. [CrossRef]

6. Dominikus, S.; Schmidt, J.-M. Connecting Passive RFID Tags to the Internet of Things. In Proceedings of the Interconnecting Smart Objects with the Internet Workshop, Prague, Czech Republic, 25 March 2011.

7. Sami, N.; Mufti, T.; Sohail, S.S.; Siddiqui, J.; Kumar, D. Future Internet of Things (IOT) from Cloud Perspective: Aspects, Applications and Challenges. In Internet of Things (IoT); Springer: New York, NY, USA, 2020; pp. 515-532.

8. Arasteh, H.; Hosseinnezhad, V.; Loia, V.; Tommasetti, A.; Troisi, O.; Shafie-khah, M.; Siano, P. Iot-Based Smart Cities: A Survey. In Proceedings of the 2016 IEEE 16th International Conference on Environment and Electrical Engineering (EEEIC), Florence, Italy, 7-10 June 2016; pp. 1-6.

9. Pontes, P.M.; Lima, B.; Faria, J.P. Test Patterns for IoT. In Proceedings of the 9th ACM SIGSOFT International Workshop on Automating TEST Case Design, Selection, and Evaluation, Lake Buena Vista, FL, USA, 5 November 2018 ; pp. 63-66.

10. Atzori, L.; Iera, A.; Morabito, G. The internet of things: A survey. Comput. Netw. 2010, 54, 2787-2805. [CrossRef]

11. Faiz, S.; Krichen, S. Geographical Information Systems and Spatial Optimization; CRC Press: Boca Raton, FL, USA, 2012.

12. Church, R.L. Geographical information systems and location science. Comput. Oper. Res. 2002, 29, 541-562. [CrossRef]

13. Burrough, P.A.; McDonnell, R.; McDonnell, R.A.; Lloyd, C.D. Principles of Geographical Information Systems; Oxford University Press: Oxford, UK, 2015.

14. DiBiase, D.; DeMers, M.; Johnson, A.; Kemp, K.; Luck, A.T.; Plewe, B.; Wentz, E. Introducing the first edition of geographic information science and technology body of knowledge. Cartogr. Geogr. Inf. Sci. 2007, 34, 113-120. [CrossRef]

15. Dold, J.; Groopman, J. The future of geospatial intelligence. Geo-Spat. Inf. Sci. 2017, 20, 151-162. [CrossRef]

16. GIS Geography. 1000 GIS Applications \& Uses-How GIS Is Changing the World. Available online: https:/ / gisgeography.com/ gis-applications-uses / (accessed on 11 December 2020).

17. Shekhar, S.; Xiong, H. Encyclopedia of GIS; Springer Science \& Business Media: Berlin, Germany, 2007.

18. Bodei, C.; Degano, P.; Ferrari, G.-L.; Galletta, L. Where do your IoT ingredients come from? In Coordination Models and Languages, Proceedings of the International Conference on Coordination Languages and Models, Heraklion, Greece, 6-9 June 2016; Springer: Cham, Switzerland, 2016; pp. 35-50.

19. Saračević, M.; Plojović, Š.; Bušatlić, S. IoT Application for Smart Cities Data Storage and Processing Based on Triangulation Method. In Internet of Things (IoT); Springer: New York, NY, USA, 2020; pp. 317-334.

20. Zhou, Q.; Zhang, J. Internet of Things and Geography-Review and Prospect. In Proceedings of the 2011 International Conference on Multimedia and Signal Processing, Guilin, China, 14-15 May 2011; IEEE: New York, NY, USA, 2011; pp. 47-51. 
21. Lopez, D.A.R.; Lopez, J.R.R.; Prieto, M.A.Z.; Quinde, L.D.S. Towards a Method for the Integration of IoT and GIS Applications Deployed on Cloud Platforms. In Proceedings of the 2017 International Conference on Information Systems and Computer Science (INCISCOS), Quito, Ecuador, 23-25 November 2017; IEEE: New York, NY, USA, 2017; pp. 353-360.

22. Ndzabandzaba, C. Participatory Geographic Information System (PGIS): A Discourse toward a Solution to Traditional GIS Challenges. In Handbook of the Changing World Language Map; Springer: New York, NY, USA, 2019; pp. 3825-3835.

23. Gold, C.M. What is GIS and What is Not? Trans. GIS 2006, 10, 505-519. [CrossRef]

24. Cao, H.; Wachowicz, M. The design of an IoT-GIS platform for performing automated analytical tasks. Comput. Environ. Urban Syst. 2019, 74, 23-40. [CrossRef]

25. Miloudi, L.; Rezeg, K. Leveraging the Power of Integrated Solutions of IoT and GIS. In Proceedings of the 2018 3rd International Conference on Pattern Analysis and Intelligent Systems (PAIS), Tebessa, Algeria, 24-25 October 2018; IEEE: New York, NY, USA, 2018.

26. Mbuh, M.; Metzger, P.; Brandt, P.; Fika, K.; Slinkey, M. Application of real-time GIS analytics to support spatial intelligent decision-making in the era of big data for smart cities. EAI Endorsed Trans. Smart Cities 2020, 4, e3. [CrossRef]

27. Ye, J.; Chen, B.; Liu, Q.; Fang, Y. A precision agriculture management system based on Internet of Things and WebGIS In Proceedings of the 2013 21st International Conference on Geoinformatics, Kaifeng, China, 20-22 June 2013; IEEE: New York, NY, USA, 2013.

28. Fang, S.; Da Xu, L.; Zhu, Y.; Ahati, J.; Pei, H.; Yan, J.; Liu, Z. An integrated system for regional environmental monitoring and management based on internet of things. IEEE Trans. Ind. Inform. 2014, 10, 1596-1605. [CrossRef]

29. Lwin, K.K.; Sekimoto, Y.; Takeuchi, W.; Zettsu, K. City Geospatial Dashboard: IoT and Big Data Analytics for Geospatial Solutions Provider in Disaster Management. In Proceedings of the 2019 International Conference on Information and Communication Technologies for Disaster Management (ICT-DM), Paris, France, 18-20 December 2019; IEEE: New York, NY, USA, 2019.

30. Patti, E.; Acquaviva, A. IoT platform for Smart Cities: Requirements and implementation case studies. In Proceedings of the 2016 IEEE 2nd International Forum on Research and Technologies for Society and Industry Leveraging a Better Tomorrow (RTSI), Bologna, Italy, 7-9 September 2016; IEEE: New York, NY, USA, 2016.

31. Cheng, Y.; Zhao, L. Application and research of GIS intelligent environmental protection Internet of things system construction technology. In Proceedings of the 2019 International Conference on Information Technology and Computer Application (ITCA), Guangzhou, China, 20-22 December 2019; IEEE: New York, NY, USA, 2019.

32. Wang, L.-q.; Jia, J.-w. A Design of Environmental Quality Management Information System Based on IOT and GIS. Environ. Sci. Surv. 2012, 3, 1-2.

33. Peng, S.; Su, G.; Chen, J.; Du, P. Design of an IoT-BIM-GIS based risk management system for hospital basic operation. In Proceedings of the 2017 IEEE Symposium on Service-Oriented System Engineering (SOSE), San Francisco, CA, USA, 6-9 April 2017; IEEE: New York, NY, USA, 2017.

34. Cisco. Cisco IoT Solutions. Available online: https://www.cisco.com/c/en/us/solutions/internet-of-things/overview.html (accessed on 11 December 2020).

35. Mittal, S.; Chadchan, J.; Mishra, S.K. Review of concepts, tools and indices for the assessment of urban quality of life. Soc. Indic. Res. 2020, 149, 187-214. [CrossRef]

36. Fazio, M.; Paone, M.; Puliafito, A.; Villari, M. Heterogeneous sensors become homogeneous things in smart cities. In Proceedings of the 2012 Sixth International Conference on Innovative Mobile and Internet Services in Ubiquitous Computing, Palermo, Italy, 4-6 July 2012; IEEE: New York, NY, USA, 2012.

37. Garau, C.; Pavan, V.M. Evaluating urban quality: Indicators and assessment tools for smart sustainable cities. Sustainability 2018, 10, 575. [CrossRef]

38. Balakrishna, C. Enabling technologies for smart city services and applications. In Proceedings of the 2012 Sixth International Conference on Next Generation Mobile Applications, Services and Technologies, Paris, France, 12-14 September 2012; IEEE: New York, NY, USA, 2012.

39. Pazhuhan, M.; Shahraki, S.Z.; Kaveerad, N.; Cividino, S.; Clemente, M.; Salvati, L. Factors underlying life quality in urban contexts: Evidence from an industrial city (Arak, Iran). Sustainability 2020, 12, 2274. [CrossRef]

40. Ebrahimzadeh, I.; Shahraki, A.A.; Shahnaz, A.A.; Myandoab, A.M. Progressing urban development and life quality simultaneously. City Cult. Soc. 2016, 7, 186-193. [CrossRef]

41. Kennedy, D.M.; Caselli, R.J.; Berry, L.L. A roadmap for improving healthcare service quality. J. Healthc. Manag. 2011 , 56, 385-402. [CrossRef]

42. Al-Turjman, F.; Malekloo, A. Smart parking in IoT-enabled cities: A survey. Sustain. Cities Soc. 2019, 49, 101608. [CrossRef]

43. Avatefipour, O.; Sadry, F. Traffic management system using IoT technology-A comparative review. In Proceedings of the 2018 IEEE International Conference on Electro/Information Technology (EIT), Rochester, MI, USA, 3-5 May 2018; IEEE: New York, NY, USA, 2018.

44. Medina, C.A.; Pérez, M.R.; Trujillo, L.C. IoT paradigm into the smart city vision: A survey. In Proceedings of the 2017 IEEE International Conference on Internet of Things (iThings) and IEEE Green Computing and Communications (GreenCom) and IEEE Cyber, Physical and Social Computing (CPSCom) and IEEE Smart Data (SmartData), Exeter, UK, 21-23 June 2017; IEEE: New York, NY, USA, 2017. 
45. Islam, N.; Marinakis, Y.; Majadillas, M.A.; Fink, M.; Walsh, S.T. Here there be dragons, a pre-roadmap construct for IoT service infrastructure. Technol. Forecast. Soc. Chang. 2020, 155, 119073. [CrossRef]

46. Park, E.; Del Pobil, A.P.; Kwon, S.J. The role of Internet of Things (IoT) in smart cities: Technology roadmap-oriented approaches. Sustainability 2018, 10, 1388. [CrossRef]

47. Palve, S.N. Application of gis in infrastructure project management. Int. J. Struct. Civ. Eng. Res. 2013, 2, 110-122.

48. Shahrour, I. Use of GIS in smart city projects. GIM Int. Worldw. Mag. Geomat. 2018, 32, $21-23$.

49. Longley, P. GIS and the development of digital urban infrastructure. Environ. Plan. B Plan. Des. 1998, 25, 53-56. [CrossRef]

50. Shaw, S.-L. GIS for Transportation. In International Encyclopedia of Geography: People, the Earth, Environment and Technology; John Wiley \& Sons: Hoboken, NJ, USA, 2016; pp. 1-9. [CrossRef]

51. O'Sullivan, D.; Morrison, A.; Shearer, J. Using desktop GIS for the investigation of accessibility by public transport: An isochrone approach. Int. J. Geogr. Inf. Sci. 2000, 14, 85-104. [CrossRef]

52. Lu, X. Develop web gis based intelligent transportation application systems with web service technology. In Proceedings of the 2006 6th International Conference on ITS Telecommunications, Chengdu, China, 21-23 June 2006; IEEE: New York, NY, USA, 2006.

53. Soni, N.; Saraswat, J. A review of IoT devices for traffic management system. In Proceedings of the 2017 International Conference on Intelligent Sustainable Systems (ICISS), Palladam, India, 7-8 December 2017; IEEE: New York, NY, USA, 2017.

54. Xiong, Z.; Sheng, H.; Rong, W.; Cooper, D.E. Intelligent transportation systems for smart cities: A progress review. Sci. China Inf. Sci. 2012, 55, 2908-2914. [CrossRef]

55. Pan, X.; Zhou, W.; Lu, Y.; Sun, N. Prediction of network traffic of smart cities based on DE-BP neural network. IEEE Access 2019, 7, 55807-55816. [CrossRef]

56. Djahel, S.; Salehie, M.; Tal, I.; Jamshidi, P. Adaptive traffic management for secure and efficient emergency services in smart cities. In Proceedings of the 2013 IEEE International Conference on Pervasive Computing and Communications Workshops (PERCOM Workshops), San Diego, CA, USA, 18-22 March 2013; IEEE: New York, NY, USA, 2013.

57. Goodchild, M.F. GIS and transportation: Status and challenges. GeoInformatica 2000, 4, 127-139. [CrossRef]

58. Miller, H.J.; Wu, Y.-H. GIS software for measuring space-time accessibility in transportation planning and analysis. GeoInformatica 2000, 4, 141-159. [CrossRef]

59. Liu, S.; Zhu, X. Accessibility analyst: An integrated GIS tool for accessibility analysis in urban transportation planning. Environ. Plan. B Plan. Des. 2004, 31, 105-124. [CrossRef]

60. Lemire, P.O.; Delcroix, B.; Audy, J.F.; Labelle, F.; Mangin, P.; Barnabé, S. GIS method to design and assess the transportation performance of a decentralized biorefinery supply system and comparison with a centralized system: Case study in southern Quebec, Canada. Biofuels Bioprod. Biorefin. 2019, 13, 552-567. [CrossRef]

61. Pantha, B.R.; Yatabe, R.; Bhandary, N.P. GIS-based highway maintenance prioritization model: An integrated approach for highway maintenance in Nepal mountains. J. Transp. Geogr. 2010, 18, 426-433. [CrossRef]

62. Giuffrida, N.; Le Pira, M.; Inturri, G.; Ignaccolo, M. Mapping with stakeholders: An overview of public participatory GIS and VGI in transport decision-making. ISPRS Int. J. Geo-Inf. 2019, 8, 198. [CrossRef]

63. Arampatzis, G.; Kiranoudis, C.T.; Scaloubacas, P.; Assimacopoulos, D. A GIS-based decision support system for planning urban transportation policies. Eur. J. Oper. Res. 2004, 152, 465-475. [CrossRef]

64. Bojan, T.M.; Kumar, U.R.; Bojan, V.M. An internet of things based intelligent transportation system. In Proceedings of the 2014 IEEE International Conference on Vehicular Electronics and Safety, Hyderabad, India, 16-17 December 2014; IEEE: New York, NY, USA, 2014.

65. Acharya, J.; Gaur, S. Edge Compression of GPS Data for Mobile IoT. In Proceedings of the 2017 IEEE Fog World Congress (FWC), Santa Clara, CA, USA, 1 November 2017; pp. 1-6.

66. Yeh, H.-T.; Chen, B.-C.; Wang, B.-X. A city parking integration system combined with cloud computing technologies and smart mobile devices. EURASIA J. Math. Sci. Technol. Educ. 2016, 12, 1231-1242. [CrossRef]

67. Du, P.; Chen, J.; Sun, Z.; Li, Y. Design of an IoT-GIS Emergency Management System for Public Road Transport Networks. In Proceedings of the 1st ACM SIGSPATIAL International Workshop on the Use of GIS in Emergency Management, Bellevue, WA, USA, 3-6 November 2015; pp. 1-4.

68. Hassanein, H.; Zorba, N.; Han, S.; Kanhere, S.S.; Shukair, M. Crowd management. IEEE Commun. Mag. 2019, 57, 18-19. [CrossRef]

69. Yu, L.J.; Wei, H.; Zheng, Z.Z.; Liu, Y.L.; Chi, T.H.; Peng, L. Review of the Integrated Researches on Internet of Things and GIS in Fire Emergency Plan. Adv. Mater. Res. 2014, 989-994, 5444-5447. [CrossRef]

70. Emmanouil, D.; Nikolaos, D. Big data analytics in prevention, preparedness, response and recovery in crisis and disaster management. In Proceedings of the 18th International Conference on Circuits, Systems, Communications and Computers (CSCC 2015), Zakynthos, Greece, 16-20 July 2015. Recent Advances in Computer Engineering Series.

71. Zafar, U.; Shah, M.A.; Wahid, A.; Akhunzada, A.; Arif, S. Exploring IoT applications for disaster management: Identifying key factors and proposing future directions. In Recent Trends and Advances in Wireless and IoT-Enabled Networks; Springer: New York, NY, USA, 2019; pp. 291-309.

72. Tran, P.; Shaw, R.; Chantry, G.; Norton, J. GIS and local knowledge in disaster management: A case study of flood risk mapping in Viet Nam. Disasters 2009, 33, 152-169. [CrossRef] 
73. Khan, F.; ur Rehman, A.; Usman, M.; Tan, Z.; Puthal, D. Performance of cognitive radio sensor networks using hybrid automatic repeat ReQuest: Stop-and-wait. Mob. Netw. Appl. 2018, 23, 479-488. [CrossRef]

74. Liu, J.; Wen, J.; Yang, K.; Shang, Z.; Zhang, H. GIS-based analysis of flood disaster risk in LECZ of China and population exposure. In Proceedings of the 2011 19th International Conference on Geoinformatics, Shanghai, China, 24-26 June 2011; IEEE: New York, NY, USA, 2011.

75. Huang, Q.; Xiao, Y. Geographic situational awareness: Mining tweets for disaster preparedness, emergency response, impact, and recovery. ISPRS Int. J. Geo-Inf. 2015, 4, 1549-1568. [CrossRef]

76. Oloruntoba, R.; Sridharan, R.; Davison, G. A proposed framework of key activities and processes in the preparedness and recovery phases of disaster management. Disasters 2018, 42, 541-570. [CrossRef]

77. Herrmann, J. Disaster Response Planning \& Preparedness. In Spiritual Care and Mental Health for Disaster Response and Recovery; Spirit; New York Disaster Interfaith Services: New York, NY, USA, 2007; pp. 11-14.

78. Fang, S.; Xu, L.; Zhu, Y.; Liu, Y.; Liu, Z.; Pei, H.; Yan, J.; Zhang, H. An integrated information system for snowmelt flood early-warning based on internet of things. Inf. Syst. Front. 2015, 17, 321-335. [CrossRef]

79. Liu, S.-J.; Zhu, G.-Q. The application of GIS and IOT technology on building fire evacuation. Procedia Eng. 2014, 71, 577-582. [CrossRef]

80. Kim, T.; Youn, J.; Kim, H.; Honglcano, J. Development of a IT-Based Volcanic Disasters Response System. In Proceedings of the Geospatial World Forum, Geneva, Switzerland, 5-9 May 2014.

81. He, Y.; Wang, D.; Chen, L. Research on The Forest Fire Monitoring System Based on GIS, GPS and Internet of Things. Comput. Knowl. Technol. 2011, 36, 100.

82. Nabil, A.M.; Mesbah, S.; Sharawi, A. Synergy of GIS and IoT for Weather Disasters Monitoring and Management. In Proceedings of the 2019 Ninth International Conference on Intelligent Computing and Information Systems (ICICIS), Cairo, Egypt, 8-10 December 2019; IEEE: New York, NY, USA, 2019.

83. Rahman, A.; Kumar, Y.; Fazal, S.; Bhaskaran, S. Urbanization and quality of urban environment using remote sensing and GIS techniques in East Delhi-India. J. Geogr. Inf. Syst. 2011, 3, 62-84. [CrossRef]

84. Bernardo, M.; Casadesus, M.; Karapetrovic, S.; Heras, I. How integrated are environmental, quality and other standardized management systems? An empirical study. J. Clean. Prod. 2009, 17, 742-750. [CrossRef]

85. Lovett, G.M.; Burns, D.A.; Driscoll, C.T.; Jenkins, J.C.; Mitchell, M.J.; Rustad, L.; Shanley, J.B.; Likens, G.E.; Haeuber, R. Who needs environmental monitoring? Front. Ecol. Environ. 2007, 5, 253-260. [CrossRef]

86. Malche, T.; Maheshwary, P.; Kumar, R. Environmental monitoring system for smart city based on secure internet of things (IoT) architecture. Wirel. Pers. Commun. 2019, 107, 2143-2172. [CrossRef]

87. Nikhil, R.; Rajender, R.; Dushyantha, G.; Jagadevi, N. Smart water quality monitoring system using IoT environment. Int. J. Innov. Eng. Technol 2018, 10, 29-31.

88. Li, Z.-W.; Zeng, G.-M.; Zhang, H.; Yang, B.; Jiao, S. The integrated eco-environment assessment of the red soil hilly region based on GIS-A case study in Changsha City, China. Ecol. Model. 2007, 202, 540-546. [CrossRef]

89. Karimipour, F.; Delavar, M.R.; Kinaie, M. Water quality management using GIS data mining. J. Environ. Inform. 2005, 5, 61-71. [CrossRef]

90. Assaf, H.; Saadeh, M. Assessing water quality management options in the Upper Litani Basin, Lebanon, using an integrated GIS-based decision support system. Environ. Model. Softw. 2008, 23, 1327-1337. [CrossRef]

91. Pal, P.; Gupta, R.; Tiwari, S.; Sharma, A. IoT based air pollution monitoring system using Arduino. Int. Res. J. Eng. Technol. (IRJET) 2017, 4, 1137-1140.

92. Islam, F; Mamun, K. GIS based water quality monitoring system in pacific coastal area: A case study for Fiji. In Proceedings of the 2015 2nd Asia-Pacific World Congress on Computer Science and Engineering (APWC on CSE), Nadi, Fiji, 2-4 December 2015; IEEE: New York, NY, USA, 2015.

93. Wilson, J. Local, national, and global applications of GIS in agriculture. In Geographical Information Systems: Management Issues and Applications; Wiley: Hoboken, NJ, USA, 1999; pp. 981-998.

94. Ahmed, A.; Shibasaki, R. Climate Change and Agricultural Food Production of Bangladesh: An IMPACT assessment Using GIS-Based Biophysical Crop Simulation Model. Available online: https://www.geospatialworld.net/article/climate-change-andagricultural-food-production-of-bangladesh-an-impact-assessment-using-gis-based-biophysical-crop-simulation-model/ (accessed on 11 December 2020).

95. Peters, C.J.; Bills, N.L.; Lembo, A.J.; Wilkins, J.L.; Fick, G.W. Mapping potential foodsheds in New York State: A spatial model for evaluating the capacity to localize food production. Renew. Agric. Food Syst. 2009, 24, 72-84. [CrossRef]

96. Eckert, J.; Shetty, S. Food systems, planning and quantifying access: Using GIS to plan for food retail. Appl. Geogr. 2011, 31, 1216-1223. [CrossRef]

97. Zhao, Q.; Jin, G.; Zhou, W.; Wang, C.; Dai, J. Information collection system for diseases and pests in cotton fieldbased on mobile GIS. Trans. Chin. Soc. Agric. Eng. 2015, 31, 183-190.

98. Zhao, P.; Liu, G.; Li, M.; Li, D. Management information system for apple diseases and insect pests based on GIS. Trans. Chin. Soc. Agric. Eng. 2006, 22, 150-154.

99. Bolo, B.; Mpoeleng, D. Mapping of crop birds pest using GPS and GIS. J. Agric. Inform. 2019, 10, 12-20. [CrossRef] 
100. Fenu, G.; Malloci, F.M. An Application of Machine Learning Technique in Forecasting Crop Disease. In Proceedings of the 2019 3rd International Conference on Big Data Research, Melbourn, Australia, 22-24 August 2019; pp. 76-82.

101. Koua, J.-J.T.; Anoh, A.K.; Soro, D.T.; Kouame, J.K.; Jourda, R.J.P. Evaluation of Agricultural Practices Scenarios for Reducing Erosion in Buyo Lake Catchment (Sassandra; Côte d'Ivoire) by Use of GIS. J. Geosci. Environ. Prot. 2019, 7, $154-171$.

102. Tsegaye, K.; Addis, H.K.; Hassen, E.E. Soil Erosion Impact Assessment using USLE/GIS Approaches to Identify High Erosion Risk Areas in the Lowland Agricultural Watershed of Blue Nile Basin, Ethiopia. Int. Ann. Sci. 2020, 8, 120-129. [CrossRef]

103. Kouli, M.; Soupios, P.; Vallianatos, F. Soil erosion prediction using the revised universal soil loss equation (RUSLE) in a GIS framework, Chania, Northwestern Crete, Greece. Environ. Geol. 2009, 57, 483-497. [CrossRef]

104. Iverson, L.; Prasad, A. Estimating regional plant biodiversity with GIS modelling. Divers. Distrib. 1998, 4, 49-61. [CrossRef]

105. Geyer, R.; Stoms, D.M.; Lindner, J.P.; Davis, F.W.; Wittstock, B. Coupling GIS and LCA for biodiversity assessments of land use: Part 1: Inventory modeling. Int. J. Life Cycle Assess. 2010, 15, 454-467. [CrossRef]

106. Parker, L.; Bourgoin, C.; Martinez-Valle, A.; Läderach, P. Vulnerability of the agricultural sector to climate change: The development of a pan-tropical Climate Risk Vulnerability Assessment to inform sub-national decision making. PLoS ONE 2019, 14, e0213641. [CrossRef]

107. Suma, N.; Samson, S.R.; Saranya, S.; Shanmugapriya, G.; Subhashri, R. IOT based smart agriculture monitoring system. Int. J. Recent Innov. Trends Comput. Commun. 2017, 5, 177-181.

108. Liqiang, Z.; Shouyi, Y.; Leibo, L.; Zhen, Z.; Shaojun, W. A crop monitoring system based on wireless sensor network. Procedia Environ. Sci. 2011, 11, 558-565. [CrossRef]

109. Jaishetty, S.A.; Patil, R. IoT sensor network based approach for agricultural field monitoring and control. IJRET Int. J. Res. Eng. Technol. 2016, 5, 44-48.

110. Dalsted, K. Introduction: Remote sensing and GIS techniques for the detection, surveillance, and management of invasive species. In GIS Applications in Agriculture, Volume Three; CRC Press: Boca Raton, FL, USA, 2011; pp. 16-23.

111. Zhao, G.; Yu, H.; Wang, G.; Sui, Y.; Zhang, L. Study on the detection and warning system of rice disease based on the GIS and IOT in Jilin Province. In Computer and Computing Technologies in Agriculture VIII, Proceedings of the International Conference on Computer and Computing Technologies in Agriculture, Beijing, China, 16-19 September 2014; Springer: New York, NY, USA, 2015 ; pp. 337-343.

112. Das, S.D.; Deb, N.; Biswal, G.R.; Das, S. High Voltage Aspects of Smart Agriculture through GIS Towards Smarter IoT. In Proceedings of the 2019 International Conference on Automation, Computational and Technology Management (ICACTM), London, UK, 24-26 April 2019; IEEE: New York, NY, USA, 2019; pp. 484-488.

113. Simmhan, Y.; Ravindra, P.; Chaturvedi, S.; Hegde, M.; Ballamajalu, R. Towards a data-driven IoT software architecture for smart city utilities. Softw. Pract. Exp. 2018, 48, 1390-1416. [CrossRef]

114. Bran, M.; Frigura-Iliasa, M.; Filipescu, H.E.; Dolga, L.; Vatau, V.; Iorga, M. Case Study about Smart Integrated Utilities for Smart Cities. In Proceedings of the 2020 IEEE 18th World Symposium on Applied Machine Intelligence and Informatics (SAMI), Herlany, Slovakia, 23-25 January 2020; IEEE: New York, NY, USA, 2020; pp. 23-26.

115. Sánchez, L.; Elicegui, I.; Cuesta, J.; Muñoz, L.; Lanza, J. Integration of utilities infrastructures in a future internet enabled smart city framework. Sensors 2013, 13, 14438-14465. [CrossRef]

116. Wang, M.; Deng, Y.; Won, J.; Cheng, J.C. An integrated underground utility management and decision support based on BIM and GIS. Autom. Constr. 2019, 107, 102931. [CrossRef]

117. Chalkias, C.; Lasaridi, K. A GIS based model for the optimisation of municipal solid waste collection: The case study of Nikea, Athens, Greece. Technology 2009, 1, 11-15.

118. Kallel, A.; Serbaji, M.M.; Zairi, M. Using GIS-Based tools for the optimization of solid waste collection and transport: Case study of Sfax City, Tunisia. J. Eng. 2016, 2016, 4596849. [CrossRef]

119. Chang, N.-B.; Lu, H.; Wei, Y. GIS technology for vehicle routing and scheduling in solid waste collection systems. J. Environ. Eng. 1997, 123, 901-910. [CrossRef]

120. Malakahmad, A.; Bakri, P.M.; Mokhtar, M.R.M.; Khalil, N. Solid waste collection routes optimization via GIS techniques in Ipoh city, Malaysia. Procedia Eng. 2014, 77, 20-27. [CrossRef]

121. Hemidat, S.; Oelgemöller, D.; Nassour, A.; Nelles, M. Evaluation of Key Indicators of Waste Collection Using GIS Techniques as a Planning and Control Tool for Route Optimization. Waste Biomass Valorization 2017, 8, 1533-1554. [CrossRef]

122. Chalkias, C.; Lasaridi, K. Optimizing municipal solid waste collection using GIS. In Proceedings of the 5th International Conference on Energy, Environment, Ecosystems and Sustainable Development/2nd International Conference on Landscape Architecture, Athens, Greece, 28-30 September 2009; pp. 45-50.

123. Anagnostopoulos, T.; Zaslavsy, A.; Medvedev, A.; Khoruzhnicov, S. Top-k query based dynamic scheduling for IoT-enabled smart city waste collection. In Proceedings of the 2015 16th IEEE International Conference on Mobile Data Management, Pittsburgh, PA, USA, 15-18 June 2015; IEEE: New York, NY, USA, 2015; pp. 50-55.

124. Anagnostopoulos, T.; Zaslavsky, A.; Medvedev, A. Robust waste collection exploiting cost efficiency of IoT potentiality in Smart Cities. In Proceedings of the 2015 International Conference on Recent Advances in Internet of Things (RIoT), Singapore, 7-9 April 2015; IEEE: New York, NY, USA, 2015.

125. Islam, M.S.; Hannan, M.; Arebey, M.; Basri, H. An overview for solid waste bin monitoring system. J. Appl. Sci. Res. 2012, 1, 879-886. 
126. Stepanova, I.A.; Stepanov, A.S. An overview of waste collection systems in anthropogenic ecosystems. Samara J. Sci. 2020, 9 , 121-131. [CrossRef]

127. Tagliabue, L.C.; Re Cecconi, F.; Moretti, N.; Rinaldi, S.; Bellagente, P.; Ciribini, A.L.C. Security Assessment of Urban Areas through a GIS-Based Analysis of Lighting Data Generated by IoT Sensors. Appl. Sci. 2020, 10, 2174. [CrossRef]

128. Pandharipande, A.; Zhao, M.; Frimout, E.; Thijssen, P. IoT lighting: Towards a connected building eco-system. In Proceedings of the 2018 IEEE 4th World Forum on Internet of Things (WF-IoT), Singapore, 5-8 Febbruary 2018; IEEE: New York, NY, USA, 2018; pp. 664-669.

129. Caicedo, D.; Pandharipande, A. Distributed illumination control with local sensing and actuation in networked lighting systems. IEEE Sens. J. 2012, 13, 1092-1104. [CrossRef]

130. Yu-de ZHANG Chang-hao, D.; Meng-meng, D.B.-y.L.; Qing-peng, Q.X.-h.D. Design of GIS-Based Digital Lighting System for City Road. J. South China Univ. Technol. (Nat. Sci.) 2016, 44, 51.

131. Kruszynski, W.; Dawidowicz, J.; Andraka, D.; Tomaszewska, J. Application and digital implementation GIS data to computer modeling of the sanitary sewage network in Podlaskie voivodship. Ekon. Śr. 2018, 65, 9.

132. Adam, K.J. Management of Sewerage Network by Using GIS. Master's Thesis, Sudan University of Science and Technology, Khartoum, Sudan, 2015.

133. Fellers, J. Implementing a Geographic Information System for a Rural Water and Sewer Company: A Case Study of the Newberry County Water and Sewer Authority: A Thesis Presented to the Department of Humanities and Social Sciences in Candidacy for the Degree of Master of Science. Ph.D. Thesis, Northwest Missouri State University, Maryville, MO, USA, 2013.

134. Patil, J.; Kulkarni, S. Design and mapping of underground sewerage network in GIS, a case study of Islampur Town. Int. J. Sci. Res. 2012, 3, 2319-7064.

135. Abdelbaki, C.; Rouissat, B.; Charef, I.; Abdelkader, A.H. Management of a Sewerage Network by Coupling GIS and Hydraulic Modeling: A Case Study of the Network of the New University in Tlemcen, Algeria. LARHYSS J. 2016, 28, 167-179.

136. Mugambi, B.K. Application of GIS and Remote Sensing in Enhancing Sewer Reticulation Networks, Case Study of Nyeri Municipality. Available online: http:/ / repository.dkut.ac.ke:8080/xmlui/handle/123456789/1179 (accessed on 11 December 2020).

137. Yoo, J. GIS-based simulation of urban sewerage flow volume. Urban Water J. 2005, 2, 1-12. [CrossRef]

138. Mohsin, A.N. Using 3D Analysis of GIS and Remote Sensing for Modeling Erbil Water Flow and Sewerage Network. Eng. Technol. J. 2010, 28, 4910-4925.

139. Tadokoro, H.; Jp, P.; Nakamura, N.; Nishimura, T.; Uemura, K.; Kikuchi, N.; Hatayama, M. Monitoring and Control Systems for the IoT in the Water Supply and Sewerage Utilities. Hitachi Rev. 2017, 66, 704-711.

140. Wang, Z.; Xu, J.; He, X.; Wang, Y. Analysis of spatiotemporal influence patterns of toxic gas monitoring concentrations in an urban drainage network based on IoT and GIS. Pattern Recognit. Lett. 2020, 138, 237-246. [CrossRef]

141. Golechha, M. Healthcare agenda for the Indian government. Indian J. Med. Res. 2015, 141, 151. [CrossRef]

142. Tomlinson, T.; Godbole, P. Opportunities and Challenges in Global Healthcare. In Hospital Transformation; Springer: New York, NY, USA, 2019; pp. 7-12.

143. Greening, N. Analysis and Reporting of Case Studies, Global Healthcare in an Aging Society. Sci. Res. J. 2019, VII. [CrossRef]

144. Higgs, G. A literature review of the use of GIS-based measures of access to health care services. Health Serv. Outcomes Res. Methodol. 2004, 5, 119-139. [CrossRef]

145. Dulin, M.F.; Ludden, T.M.; Tapp, H.; Blackwell, J.; de Hernandez, B.U.; Smith, H.A.; Furuseth, O.J. Using Geographic Information Systems (GIS) to understand a community's primary care needs. J. Am. Board Fam. Med. 2010, 23, 13-21. [CrossRef]

146. Dogru, A.O.; David, R.M.; Ulugtekin, N.; Goksel, C.; Seker, D.Z.; Sözen, S. GIS based spatial pattern analysis: Children with Hepatitis A in Turkey. Environ. Res. 2017, 156, 349-357. [CrossRef]

147. Bui, T.Q.; Pham, H.M. Web-based GIS for spatial pattern detection: Application to malaria incidence in Vietnam. SpringerPlus 2016, 5, 1014. [CrossRef]

148. Mollalo, A.; Mao, L.; Rashidi, P.; Glass, G.E. A GIS-based artificial neural network model for spatial distribution of tuberculosis across the continental United States. Int. J. Environ. Res. Public Health 2019, 16, 157. [CrossRef]

149. Rai, P.K.; Nathawat, M.S. GIS in Healthcare Planning: A Case Study of Varanasi, India. Forum Geografic 2013, 12, 153-163. [CrossRef]

150. Elmes, G.A. 13 GIS in Public Healthcare Planning: The United States Perspective. In GIS in Public Health Practice; CRC Press: Boca Raton, FL, USA, 2016; p. 205.

151. Kim, Y.; Byon, Y.-J.; Yeo, H. Enhancing healthcare accessibility measurements using GIS: A case study in Seoul, Korea. PLoS ONE 2018, 13, e0193013. [CrossRef]

152. Dejen, A.; Soni, S.; Semaw, F. Spatial accessibility analysis of healthcare service centers in Gamo Gofa Zone, Ethiopia through Geospatial technique. Remote Sens. Appl. Soc. Environ. 2019, 13, 466-473. [CrossRef]

153. Lu, D.; Liu, T. The application of IOT in medical system. In Proceedings of the 2011 IEEE International Symposium on IT in Medicine and Education, Guangzhou, China, 9-11 December 2011; IEEE: New York, NY, USA, 2011; pp. $272-275$.

154. Babu, B.S.; Srikanth, K.; Ramanjaneyulu, T.; Narayana, I.L. IoT for healthcare. Int. J. Sci. Res. 2016, 5, 322-326. 
155. Kodali, R.K.; Swamy, G.; Lakshmi, B. An implementation of IoT for healthcare. In Proceedings of the 2015 IEEE Recent Advances in Intelligent Computational Systems (RAICS), Trivandrum, India, 10-12 December 2015; IEEE: New York, NY, USA, 2015; pp. 411-416.

156. Shankar, K.; Ilayaraja, M.; Kumar, K.S. Technological Solutions for Health Care Protection and Services through Internet of Things (IoT). Int. J. Pure Appl. Math. 2018, 118, 277-283.

157. Yeole, A.S.; Kalbande, D.R. Use of Internet of Things (IoT) in healthcare: A survey. In Proceedings of the ACM Symposium on Women in Research, Indore, India, 21-22 March 2016; pp. 71-76.

158. Termeh, V.R.; Niaraki, A.S. Design and Implementation of Ubiquitous Health System (U-Health) Using Smart-Watches Sensors. Int. Arch. Photogramm. Remote Sens. Spat. Inf. Sci. 2015, XL, 607-612. [CrossRef]

159. Sethi, P.; Sarangi, S.R. Internet of things: Architectures, protocols, and applications. J. Electr. Comput. Eng. 2017, $2017,9324035$. [CrossRef]

160. Farooq, M.U.; Waseem, M.; Mazhar, S.; Khairi, A.; Kamal, T. A review on internet of things (IoT). Int. J. Comput. Appl. 2015, 113, $1-7$.

161. Said, O.; Masud, M. Towards internet of things: Survey and future vision. Int. J. Comput. Netw. 2013, 5, 1-17.

162. Chen, W. An IBE-Based Security Scheme on Internet of Things. In Proceedings of the 2012 IEEE 2nd International Conference on Cloud Computing and Intelligence Systems, Hangzhou, China, 1 November 2012; pp. 1046-1049.

163. Khan, R.; Khan, S.U.; Zaheer, R.; Khan, S. Future internet: The internet of things architecture, possible applications and key challenges. In Proceedings of the 2012 10th International Conference on Frontiers of Information Technology, Islamabad, Pakistan, 17-19 December 2012; IEEE: New York, NY, USA, 2012; pp. 257-260.

164. Mashal, I.; Alsaryrah, O.; Chung, T.-Y.; Yang, C.-Z.; Kuo, W.-H.; Agrawal, D.P. Choices for interaction with things on Internet and underlying issues. Ad Hoc Netw. 2015, 28, 68-90. [CrossRef]

165. Bandyopadhyay, D.; Sen, J. Internet of things: Applications and challenges in technology and standardization. Wirel. Pers. Commun. 2011, 58, 49-69. [CrossRef]

166. Zhang, Y. Technology framework of the Internet of Things and its application. In Proceedings of the 2011 International Conference on Electrical and Control Engineering, Yichang, China, 16-18 September 2011; IEEE: New York, NY, USA, 2011 ; pp. $4109-4112$.

167. Maguire, D.J. An overview and definition of GIS. Geogr. Inf. Syst. Princ. Appl. 1991, 1, 9-20.

168. Chang, K.T. Geographic information system. Int. Encycl. Geogr. People Earth Environ. Technol. 2016, 1-9. [CrossRef]

169. Liu, Y.; Zhang, W.; Cui, X.; Zhang, G.; Wang, G. City pipe network intelligent service based on GIS and internet of things. In Proceedings of the 2014 7th International Conference on Intelligent Computation Technology and Automation, Changsha, China, 25-26 October 2014; IEEE: New York. USA, 2014; pp. 936-939.

170. Nourjou, R.; Hashemipour, M. Smart Energy Utilities Based on Real-Time GIS Web Services and Internet of Things. Procedia Comput. Sci. 2017, 110, 8-15. [CrossRef]

171. Konomi, S.I.; Roussos, G. Enriching Urban Spaces with Ambient Computing, the Internet of Things, and Smart City Design; IGI Global: Pennsylvania, PA, USA, 2016.

172. Bhanumathi, V.; Kalaivanan, K. The role of geospatial technology with IoT for precision agriculture. In Cloud Computing for Geospatial Big Data Analytics; Springer: New York, NY, USA, 2019; pp. 225-250.

173. Lv, Z.; Li, X.; Lv, H.; Xiu, W. BIM big data storage in WebVRGIS. IEEE Trans. Ind. Inform. 2019, 16, 2566-2573. [CrossRef]

174. Zhao, Q.; Feng, J.P.; Li, T.; Jin, L. Research on application of sensor monitoring technology based on the IOT in the campus GIS pipeline system. Appl. Mech. Mater. 2014, 668-669, 944-947. [CrossRef]

175. Yang, J.; Han, Y.; Wang, Y.; Jiang, B.; Lv, Z.; Song, H. Optimization of real-time traffic network assignment based on IoT data using DBN and clustering model in smart city. Future Gener. Comput. Syst. 2020, 108, 976-986. [CrossRef]

176. Butgereit, L.L. Using GeoHashes to Combine IOT and GIS to Provide Business Intelligence to the Informal Sector in South Africa. In Proceedings of the 35th International Conference on Computers and Their Applications, San Francisco, CA, USA, 23-25 March 2020; pp. 90-97.

177. Priya, R.V.; Sivaranjani, S.; Sivakumari, S. GIS enabled internet of things (IoT) applications: An overview. World Sci. News 2016, $41,143$.

178. Lin, X. Logistic geographical information detecting unified information system based on Internet of Things. In Proceedings of the 2011 IEEE 3rd International Conference on Communication Software and Networks, Xi'an, China, 27-29 May 2011; IEEE: New York, NY, USA, 2011; pp. 303-307.

179. Isikdag, U. BIM and IoT: A synopsis from GIS perspective. Int. Arch. Photogramm. Remote Sens. Spat. Inf. Sci. 2015, 40, 33-38. [CrossRef]

180. Nordrum, A. The internet of fewer things [news]. IEEE Spectr. 2016, 53, 12-13. [CrossRef]

181. Chase, J. The evolution of the internet of things. Tex. Instrum. 2013, 1, 1-7.

182. van der Zee, E.; Scholten, H. Spatial dimensions of big data: Application of geographical concepts and spatial technology to the internet of things. In Big Data and Internet of Things: A Roadmap for Smart Environments; Springer: New York, NY, USA, 2014; pp. 137-168.

183. Kamilaris, A.; Ostermann, F. Geospatial Analysis and Internet of Things in Environmental Informatics. arXiv 2018, arXiv:1808.01895.

184. Li, Y.; Tan, K.C.; Xie, M. Measuring web-based service quality. Total Qual. Manag. 2002, 13, 685-700. [CrossRef]

185. Fu, P. Getting to Know Web GIS, 4th ed.; Esri Press: Redlands, CA, USA, 2016. 
186. Alesheikh, A.A.; Helali, H.; Behroz, H. Web GIS: Technologies and its applications. In Symposium on Geospatial Theory, Processing and Applications; ISPRS: Hannover, Germany, 2002.

187. Chen, F.; Yang, C.; Yu, W.; Le, X.; Yang, J. Research on mobile GIS based on LBS. In Proceedings of the 2005 IEEE International Geoscience and Remote Sensing Symposium, IGARSS'05, Seoul, Korea, 29 July 2005; IEEE: New York, NY, USA, 2005.

188. Tsou, M.-H. Integrated mobile GIS and wireless internet map servers for environmental monitoring and management. Cartogr. Geogr. Inf. Sci. 2004, 31, 153-165. [CrossRef] 